\title{
Alcoholic Liver Disease and COVID-19 Pneumonia: A Case Series
}

\author{
Devika Kapuria*1, Shubhra Upadhyay ${ }^{2}$, Rahul Shekhar ${ }^{2}$ and Euriko Torrazza-Perez ${ }^{1}$ \\ ${ }^{1}$ Department of Gastroenterology, University of New Mexico Health Science Center, Albuquerque, NM, USA; ${ }^{2}$ Department of \\ Internal Medicine, University of New Mexico Health Science Center, Albuquerque, NM, USA
}

\begin{abstract}
The novel coronavirus 2019 (COVID-19) was reported by the World Health Organization in December 2019, and since then it has progressed into a worldwide pandemic, causing significant morbidity and mortality. Gastrointestinal symptoms of COVID19 and elevated liver chemistries are seen in up to $50 \%$ of infected patients. Recent reports have suggested a high mortality rate for COVID-19 in patients with pre-existing liver disease, having an associated mortality of $39.8 \%$. Alcoholic liver disease is a significant cause of morbidity and mortality in New Mexico (USA), and we report here the clinical course and characteristics of three cases of patients with alcoholic cirrhosis who were admitted to our hospital with COVID-19.

Citation of this article: Kapuria D, Upadhyay S, Shekhar R, Torrazza-Perez E. Alcoholic liver disease and COVID-19 pneumonia: A case series. J Clin Transl Hepatol 2020;8(4):463466. doi: $10.14218 / \mathrm{JCTH} .2020 .00053$.
\end{abstract}

\section{Introduction}

The first case of novel coronavirus 2019 (COVID-19) in the USA was reported on January $20,2020 .{ }^{1}$ The USA now has the largest number of confirmed cases in the world; as of July 15,2020 , there were $3,448,625$ cases of coronavirus diagnosed in the country, with 136,699 deaths. ${ }^{2}$ While liver abnormalities have been reported in patients with coronavirus, most of the related biomarker elevations are mild, with a predominantly hepatocellular elevation ranging from $14-53 \%$ and slightly elevated bilirubin in $14-53 \%$ of patients. ${ }^{3,4}$

There is limited evidence on the outcomes of COVID-19 in patients with alcoholic liver disease. A meta-analysis showed $3 \%$ prevalence of chronic liver disease in patients with COVID-19. ${ }^{5}$ Bangash et al. ${ }^{6}$ considered that abnormal liver biochemistries do not necessarily arise from the liver alone; in fact, several other reasons, such as COVID-19-induced myositis as well as collateral liver damage from induction of

Keywords: COVID-19; Alcoholic liver disease; ARDS; Acute kidney injury. Abbreviations: AKI, acute kidney injury; ALP, alkaline phosphatase; ALT, alanine aminotransferase; ARDS, adult respiratory distress syndrome; AST, aspartate aminotransferase; BMI, body mass index; CK, creatinine kinase; COVID-19, novel coronavirus 2019; CRRT, continuous renal replacement therapy; Fio2, fraction of inspired oxygen; INR, international normalized ratio; MELD-Na, model for end-stage liver disease, sodium; $\mathrm{Na}$, sodium; PEEP, positive end-expiratory pressure; PT, prothrombin time.

Received: 7 June 2020; Revised: 16 July 2020; Accepted: 1 October 2020

* Correspondence to: Devika Kapuria, Department of Gastroenterology, University of New Mexico Health Science Center. 1 University Drive, Albuquerque, NM 87106, USA. Tel: +1-505-925-6000, E-mail: devika.kapuria@salud.unm.edu a dysregulated immune response and drug-related liver injury, are more likely to explain deranged liver biochemistries in COVID-19.

In data collected from seven Chinese studies, mortality occurred in only $0-2 \%$ of patients with chronic liver disease; however, the nature and severity of the liver disease were unknown. ${ }^{6}$ The SECURE-Cirrhosis registry and COVID-HEP reported on 334 patients with cirrhosis, out of which 102 $(31 \%)$ patients had alcoholic cirrhosis; however, outcomes were not defined by etiology of cirrhosis. ${ }^{7}$ Our hospital is a tertiary care center in a state with disproportionately excessive alcohol use and alcohol-related liver disease deaths (22 per 100,000 population $)^{8}$ compared with other USA states. In this case series, we describe the clinical presentation, management, and outcomes of patients with alcoholic cirrhosis and COVID-19.

\section{Case report}

A retrospective chart search was performed (under institutional IRB 20-186) for patients with a past medical history of alcoholic cirrhosis and diagnosis of COVID-19. The patients had been consecutively admitted to the University of New Mexico Hospital from December 1, 2019, to April 23, 2020. Informed consent was waived as part of the institutional IRB. Only patients with a laboratory-confirmed (reverse transcription-PCR-positive) diagnosis for COVID-19 were included.

Information was collected regarding comorbidities, social history, vital signs, demographics, clinical characteristics, symptomatology, alcohol use, lab results, imaging characteristics, and clinical management details. The authors manually analyzed the data.

\section{Case 1}

A 32-year-old male with a past medical history of alcoholic cirrhosis, and class I obesity [body mass index (BMI) of 30.5], presented intubated and sedated after he was found unresponsive at home. Baseline model for end-stage liver disease (MELD) labs were not available; however, per his family, the patient was a heavy drinker and was actively drinking alcohol up to 2 days before.

On evaluation, the patient was in multiorgan failure, attributed to septic shock due to COVID pneumonia. He required significant vasopressor support, acute hypoxemic respiratory failure due to acute respiratory distress syndrome (ARDS), requiring mechanical ventilation, and acute kidney injury (AKI) requiring continuous renal replacement therapy (CRRT). His physical exam was significant for bruising on his 
extremities, diffuse anasarca, and jaundice. Liver biochemistries on presentation were an aspartate aminotransferase (AST) level of $276 \mathrm{U} / \mathrm{L}$, alanine aminotransferase (ALT) level of $60 \mathrm{U} / \mathrm{L}$, and alkaline phosphatase (ALP) level of $269 \mathrm{U} / \mathrm{L}$. Total bilirubin was elevated to $15 \mathrm{mg} / \mathrm{dL}$ and direct bilirubin to $10.4 \mathrm{mg} / \mathrm{dL}$. MELD-sodium (MELD-Na) on presentation was 36 , and Child-Pugh class was C. Coagulation profile was deranged as well, with a prothrombin time (PT) 29s and international normalized ratio (INR) of 2.4. D-dimer was elevated at $6951 \mu \mathrm{g} / \mathrm{mL}$, and platelet count was $92,000 / \mathrm{mL}$. He was also severely hyponatremic, with serum sodium of $116 \mathrm{mg} / \mathrm{dL}$, and anuric, with serum creatinine of $4.81 \mathrm{mg} / \mathrm{dL}$. Lactate dehydrogenase was elevated to $609 \mathrm{U} / \mathrm{L}$. A nasopharyngeal swab returned positive for COVID-19. Serologies for hepatitis $A, B$, and $C$ were performed and were negative.

The elevated INR, D-dimer, ferritin, lactate dehydrogenase and $\mathrm{C}$-reactive protein were thought to be due the increased inflammatory response seen with COVID-19, and the patient's respiratory deterioration was thought to be due to the effects of COVID-19. Therapeutic-dose heparin was, therefore, not started. Computed tomography scans of the chest and abdomen were performed at day 12 of his hospitalization, and while this was not arterially gated, no large pulmonary embolus was noted. A bedside echogram was also performed, which did not show evidence of right heart strain. A peripheral blood smear did not show any evidence of schistocytes.
On day 3 of hospitalization, the patient's cardiopulmonary status began to improve, with decreased fraction of inspired oxygen ( $\mathrm{FiO} 2$ ) and positive end-expiratory pressure (PEEP) requirements. Unfortunately, he continued to be oliguric and in hepatic failure, with an AST of $317 \mathrm{U} / \mathrm{L}, \mathrm{ALT}$ of $110 \mathrm{U} / \mathrm{L}$, bilirubin of $17.8 \mathrm{mg} / \mathrm{dL}$, and INR of 1.64 (Table 1). Also, he experienced an acute gastrointestinal bleed, with a drop in hemoglobin from $12.4 \mathrm{~g} / \mathrm{dL}$ on admission to $7 \mathrm{~g} / \mathrm{dL}$, with coffee-ground contents in his nasogastric tube on suction and melena requiring $3 \mathrm{U}$ of packed red blood cells as well as vitamin $\mathrm{K}$ administration. Octreotide and proton pump inhibitor infusions were started, and on day 2, overt bleeding had stopped, and no endoscopic intervention was performed. He also received a 10-day course of azithromycin and hydroxychloroquine, according to an ongoing hospital-based clinical trial (unpublished data). A computed tomography scan of his abdomen showed extensive ascites and a nodular-appearing liver as well as dilated bowel loops suggestive of shock bowel. Unfortunately, his septic shock continued to worsen with leukocytosis, poor oxygenation, and elevated lactate levels, and care was withdrawn per family wishes on day 13 .

\section{Case 2}

A 34-year-old male with a known history of alcoholic cirrhosis, Class II obesity (BMI of 35) and active alcohol use was brought into the hospital intubated and sedated, after

Table 1. Characteristics of cases

\begin{tabular}{|c|c|c|c|}
\hline & Case 1 & Case 2 & Case 3 \\
\hline Age in years & 32 & 34 & 44 \\
\hline Sex & Male & Male & Male \\
\hline$B M I$ in $\mathbf{k g} / \mathbf{m}^{2}$ & 30.5 & 35 & 41.7 \\
\hline Symptoms reported & $\begin{array}{l}\text { Chills, myalgias, and } \\
\text { encephalopathy }\end{array}$ & $\begin{array}{l}\text { Dyspnea, abdominal pain, } \\
\text { and encephalopathy }\end{array}$ & Dyspnea, cough \\
\hline Comorbidities & $\begin{array}{l}\text { Alcohol use disorder } \\
\text { Obesity } \\
\text { Tobacco abuse disorder }\end{array}$ & $\begin{array}{l}\text { Alcohol use disorder } \\
\text { Obesity }\end{array}$ & $\begin{array}{l}\text { Alcohol use disorder } \\
\text { History of spontaneous } \\
\text { bacterial peritonitis } \\
\text { Hypertension } \\
\text { Pulmonary hypertension } \\
\text { Obesity }\end{array}$ \\
\hline Anticoagulation administered & $\begin{array}{l}\text { Heparin (deep vein } \\
\text { thrombosis prophylaxis) }\end{array}$ & None & $\begin{array}{l}\text { Heparin (deep vein } \\
\text { thrombosis prophylaxis) }\end{array}$ \\
\hline Length of stay in days & 13 & 2 & 6 \\
\hline $\mathrm{Na}, 134-144 \mathrm{mmol} / \mathrm{L}$ & 116 & 132 & 134 \\
\hline $\begin{array}{l}\text { PT, 9.4- } 15.4 \text { s/INR, } 0.8-1.3 \\
\text { ratio }\end{array}$ & $29.2 / 2.43$ & $16.8 / 1.41$ & $15.3 / 1.29$ \\
\hline $\begin{array}{l}\text { Total protein/albumin, 6.1-8.1/ } \\
\text { 3.4-4.7 g/dL }\end{array}$ & $5.6 / 2.3$ & $4.8 / 1.8$ & $5.1 / 1.0$ \\
\hline $\mathrm{Cr}, 0.62-1.66 \mathrm{mg} / \mathrm{dL}$ & 4.81 & 4.25 & 1.71 \\
\hline AST, 6-58 U/L & 276 & 4969 & 73 \\
\hline ALT, 14-67 U/L & 60 & 6350 & 39 \\
\hline ALP, 38-150 U/L & 269 & 160 & 147 \\
\hline $\begin{array}{l}\text { Total bilirubin/direct bilirubin, } \\
0.3-1.2 / 0.1-0.4 \mathrm{mg} / \mathrm{dL}\end{array}$ & $15.1 / 10.4$ & $5.1 / 3.6$ & $2.7 / 1.4$ \\
\hline $\begin{array}{l}\text { Procalcitonin, }<0.10 \mathrm{ng} / \mathrm{mL} / \\
\text { lactate, } 0.4-2.0 \mathrm{mmol} / \mathrm{L}\end{array}$ & $1.59 / 2.2$ & $1.58 / 13.3$ & $0.12 / 1.7$ \\
\hline
\end{tabular}


presenting to a peripheral hospital with abdominal pain and shortness of breath. His physical exam was unremarkable. He had severely deranged liver biochemistries, with an AST of $4969 \mathrm{U} / \mathrm{L}, \mathrm{ALT}$ of $6350 \mathrm{U} / \mathrm{L}$, ALP of $160 \mathrm{U} / \mathrm{L}$, and bilirubin of 5.1 $\mathrm{mg} / \mathrm{dL}$. MELD-Na on presentation was 32 and Child-Pugh class was C. Creatinine kinase (CK) was elevated to $2095 \mathrm{U} / \mathrm{L}$ and lactate was elevated to $13 \mathrm{~m} / \mathrm{g} / \mathrm{dL}$, suggesting ischemic hepatitis in the setting of shock. Platelet count was low at $54,000 / \mathrm{dL}$, and his coagulation panel was abnormal, with an INR of 1.4. A nasopharyngeal swab was positive for COVID19. Tests for markers of acute and chronic hepatitis A, B and C were negative. During the day, his hemodynamic instability worsened, requiring the addition of a fourth pressor and stress-dose hydrocortisone. CRRT was initiated, and inhaled nitric oxide was administered due to persistent hypoxemia. Despite all interventions, he continued to deteriorate and died of septic shock, presumed due to COVID-19 pneumonia.

\section{Case 3}

A 44-year-old man with Class III obesity (BMI of 41.7) and alcoholic cirrhosis complicated by esophageal varices, as well as a history of spontaneous bacterial peritonitis and pulmonary hypertension was transferred to our hospital for acute hypoxemic respiratory failure secondary to COVID-19, requiring intubation and vasopressor support. His physical exam was significant for diffuse anasarca and jaundice.

Liver biochemistries on admission showed an AST of $73 \mathrm{U} /$ $\mathrm{L}$, ALT of $19 \mathrm{U} / \mathrm{L}$, ALP of $147 \mathrm{U} / \mathrm{L}$, and bilirubin of $2.7 \mathrm{mg} / \mathrm{dL}$. MELD-Na on presentation was 21 and Child-Pugh class was C. The patient's INR was 1.29 , with a PT of $15.3 \mathrm{~s}$ and creatinine of $1.71 \mathrm{mg} / \mathrm{dL}$. Platelet count was low at $88,000 / \mathrm{mL}$. He was started on CRRT due to oliguric AKI, azithromycin, and hydroxychloroquine were administered per an ongoing clinical trial (unpublished data). While his liver biochemistries remained stable, he developed severe encephalopathy, and his cardiopulmonary status continued to worsen. Due to his poor prognosis and lack of improvement, his family decided to withdraw care, and he died 6 days after admission.

\section{Discussion}

Our cases represent the only patients presenting with alcoholic cirrhosis and COVID-19 to our tertiary hospital through the study period, ${ }^{9}$ representing a $100 \%$ mortality rate. The severity of liver disease at baseline was not known in cases 1 and 2 , as they were transferred from an outside facility with no available medical records; however, case 3 had decompensated cirrhosis with varices as well as a history of spontaneous bacterial peritonitis. All patients were obese, with an average BMI of 35.7 (BMI > 30 in all) and were actively drinking before symptom onset. All patients required critical care with aggressive cardiopulmonary resuscitation. All three patients experienced a profound cardiopulmonary collapse, suggestive of septic shock due to COVID-19 pneumonia; however, with the presence of elevated inflammatory markers, COVID-19induced cytokine storm cannot be ruled out.

Two patients had elevated hepatocellular biochemistries, up to 10 times the upper limit of normal (case 2 likely due to ischemic hepatitis); however, all three patients had disproportional direct hyperbilirubinemia, likely due to the hepatic decompensation in the setting of alcoholic cirrhosis. Two out of the three patients (case 1 and case 3 ) were started on prophylactic heparin for increased thromboembolic risk. No gastrointestinal bleeding was seen in case 3, although he had known esophageal varices. Case 1 had coffee ground-like material in his nasogastric tube as well as melena, and required blood transfusions. An endoscopy was deferred due to his clinical condition. His bleeding stopped with octreotide administration.

The severity of illness in these cases ( three men below the age of 45 ( with alcoholic cirrhosis and COVID-19 corroborates with the high percentage of deaths reported by Moon et al. ${ }^{7}$ In addition to obesity, which is already a known risk factor for poor outcomes, ${ }^{10}$ a history of alcoholic cirrhosis and active drinking points towards hepatic decompensation worsening morbidity. Direct kidney involvement in COVID-19 was reported to be low, at only $4.5 \% ;{ }^{11}$ however, subsequent analyses from Italy showed the prevalence to be as high as $15 \%,{ }^{12}$ especially in patients with severe disease in the Intensive Care Unit setting. All three of our patients required CRRT to address oliguric AKI. While other reasons, including cytokine damage, organ crosstalk and systemic effects, have been cited, ${ }^{13}$ dysfunction of the hepatorenal axis should also be considered. The requirement of mechanical ventilation is yet another poor prognostic factor in patients with COVID-19, which may have also contributed to the outcomes in our case series. ${ }^{14}$

We believe these cases are an example of a unique set of problems faced by hepatologists and critical care teams managing COVID-19 patients with decompensated liver disease. Recognition and discussion of a poor prognosis should be considered early on in these patients. Gastrointestinal bleeding, as well as secondary infections, should be recognized and managed promptly. Finally, as a preventative measure, hepatologists should reinforce the importance of abstinence during outpatient visits in patients with alcoholic liver disease.

\section{Funding}

None to declare.

\section{Conflict of interest}

The authors have no conflict of interests related to this publication.

\section{Author contributions}

Conception of the study, writing of the paper (DK, RS), data collection (SU, RS), critical review and writing of the paper (ET, DK).

\section{References}

[1] Holshue ML, DeBolt C, Lindquist S, Lofy KH, Wiesman J, Bruce H, et al. First case of 2019 novel coronavirus in the United States. N Engl J Med 2020;382: 929-936. doi: 10.1056/NEJMoa2001191.

[2] Coronavirus resource center. Available from: https://coronavirus.jhu. edu/map.html.

[3] Jin X, Lian JS, Hu JH, Gao J, Zheng L, Zhang YM, et al. Epidemiological, clinical and virological characteristics of 74 cases of coronavirus-infected disease 2019 (COVID-19) with gastrointestinal symptoms. Gut 2020;69: 1002-1009. doi: 10.1136/gutjnl-2020-320926.

[4] Xu L, Liu J, Lu M, Yang D, Zheng X. Liver injury during highly pathogenic human coronavirus infections. Liver Int 2020;40:998-1004. doi: 10. 1111/liv. 14435.

[5] Mantovani A, Beatrice G, Dalbeni A. Coronavirus disease 2019 and prevalence of chronic liver disease: A meta-analysis. Liver Int 2020;40:13161320. doi: 10.1111/liv.14465. 
[6] Bangash MN, Patel J, Parekh D. COVID-19 and the liver: little cause for concern Lancet Gastroenterol Hepatol 2020;5:529-530. doi: 10.1016/S2468-1253(20) 30084-4 .

[7] Moon AM, Webb GJ, Aloman C, Armstrong MJ, Cargill T, Dhanasekaran R, et al. High mortality rates for SARS-CoV-2 infection in patients with pre-existing chronic liver disease and cirrhosis: Preliminary results from an international registry. J Hepatol 2020;73:705-708. doi: 10.1016/j.jhep.2020.05.013 .

[8] Deparment of Health. NM-IBIS - Health Indicator Report - Alcohol - AlcoholRelated Chronic Liver Disease Deaths. Available from: https://ibis.health. state.nm.us/indicator/view/AlcoholRelatedDthLiver.Year.NM_US.html.

[9] Shekhar R, Sheikh AB, Upadhyay S, Atencio J, Kapuria D. Early experience with COVID-19 patients at academic hospital in Southwestern United States. Infect Dis (Lond) 2020;52:596-599. doi: 10.1080/23744235.2020. 1774645 .

[10] Simonnet A, Chetboun M, Poissy J, Raverdy V, Noulette J, Duhamel A, et al. High prevalence of obesity in severe acute respiratory syndrome coronavi- rus-2 (SARS-CoV-2) requiring invasive mechanical ventilation. Obesity (Silver Spring) 2020;28:1195-1199. doi: 10.1002/oby.22831.

[11] Wu C, Chen X, Cai Y, Xia J, Zhou X, Xu S, et al. Risk factors associated with acute respiratory distress syndrome and death in patients with coronavirus disease 2019 pneumonia in Wuhan, China. JAMA Intern Med 2020;180:934943. doi: 10.1001/jamainternmed.2020.0994.

[12] Webinar: COVID19. for the nephrologist: Real-life experience from Italy. Available from: https://academy.theisn.org/isn/2020/covid-19/290431/prof. vivekanand.jha.doctor.francesco.iannuzzella.26.doctor.arvind.canchi.html? $\mathrm{f}=\mathrm{menu} \% 3 \mathrm{D} 13 \% 2 \mathrm{Abrowseby} \% 3 \mathrm{D} 8 \% 2$ Asortby\%3D2\%2Alabel\%3D19791.

[13] Ronco C, Reis T. Kidney involvement in COVID-19 and rationale for extracorporeal therapies. Nat Rev Nephrol 2020;16:308-310. doi: 10. 1038/s41581-020-0284-7.

[14] Shalimar, Elhence A, Vaishnav M, Kumar R, Pathak P, Soni KD, et al. Poor outcomes in patients with cirrhosis and Corona Virus Disease-19. Indian J Gastroenterol 2020;39:285-291. doi: 10.1007/s12664-020-01074-3. 